\title{
G proteins: binary switches in health and disease
}

\author{
MUHAMMAD SOHAIL AFZAL
}

Department of Life Sciences, School of Science, University of Management and Technology (UMT), Lahore, Pakistan

\begin{abstract}
Cell signaling plays critical role in health and disease. The normal functioning of body depends on the homeostasis of immunity players. One of the very important cell signaling participants is $G$ protein-coupled receptor (GPCR). GPCRs transduce extracellular signals into target cell by binding to and activating different $G$ proteins ( $G \alpha \beta \gamma$, families $G i, G s, G q / 11, G 12 / 13)$ leading to range of different functions. Abnormal GPCRs signaling leads to various abnormalities, including but not limited to, cancer, pain, cardiac problems, and asthma. Mutations, which lead to activation or inactivation of GPCR pathways, permanently alter the pathways controlled by these receptors. A large number of human cancer incidence is a consequence of genetic abnormalities in signaling pathways, which influence cell division. Some bacteria and pathogens may interfere with the GPCR signaling pathways for their survival and immune evasion. Inhibition of GPCR signaling by small inhibitors is a novel way to treat various pathological conditions. There are several types of GPCRs in human genome, which due to their central role in health and disease, are the target of many commercially available drugs. Importantly, GPCRs have huge impact on drug discovery and approximately $30 \%$ of current drug targets are GPCRs. There is a need of further studies to explore more the role of G protein and the GPCRs in human health and how certain mutations can lead to disease state. Such studies may be important to adjust the signaling pathways for health improvement.
\end{abstract}

Key words: G proteins-coupled receptors, GPCR, immunity, health, disease.

(Cent Eur J Immunol 2020; 45 (3): 364-367)

\section{Introduction}

Cell signaling plays a vital role in growth and development. There are various cells signaling mechanisms, but one of the particularly important ones is the G protein-coupled receptor (GPCR), mostly found in eukaryotes. These receptors linked with the membrane of guanosine nucleotide are also known as "seven-transmembrane domain receptors" [1], seven transmembrane (TM) $\alpha$ helical domains presenting unique property. In these $\alpha$ helices, amino terminal is extracellular, and carboxyl terminal is intracellular. Such $\alpha$ helices relate to three extracellular and intracellular loops. Extracellular loops contain conserved cysteine residues, which stabilize the structure of receptor through disulfide bridge [2]. Intracellular loop contains Ser or Tyr residues, and plays a role in phosphorylation and receptor desensitization. In human genome, 880 GPCRs are encoded for the detection of hormones, growth factors, and other endogenous ligands. Many of these receptors behave like olfactory and gustatory receptors. They can recognize chemical and extracellular signals. Moreover, they store messages in the form of peptides, sugars, proteins, lipids, and light energy, and convey the information to the other cells. They are highly specific in their functions [3, 4].

When a cell receives an external signal by binding with GPCR, conformational changes occur in GPCR. They can bind to guanosine triphosphate (GTP) and guanosine diphosphate (GDP). GPCR contain three different subunits known as heterotrimeric (i.e., $\alpha, \beta$, and $\gamma$ subunit) protein. By lipid anchoring of $\alpha$ and $\gamma$ attached to the cell membrane, $\alpha$ subunit can connect with active (GTP) or inactive (GDP). When no signal is present, GDP will bind to the $\alpha$ subunit and a conformational change will occur in GPCR. Activation of G protein results in the replacement of GDP by GTP and the protein separates into two parts as $\alpha$ subunit and $\beta-\gamma$ dimer [5].

\section{Role in health and disease}

Many GPCRs for chemokines, hormones, neurotransmitters, neuropeptides, and autocrine and paracrine signaling molecules, interact with $\mathrm{G}$ proteins to perform their functions in target cells [6]. GPCRs transmit extracellular signals into target cell by binding to and activating different $\mathrm{G}$ proteins ( $\mathrm{G} \alpha \beta \gamma$, families $\mathrm{Gi}, \mathrm{Gs}, \mathrm{Gq} / 11, \mathrm{G} 12 / 13$ ) 
[7]. G proteins are categorized into 04 families according to their $\alpha$ subunits. These families are classified as Gi, Gs, G12/13, and Gq. Among these, Gs and Gi families regulate adenylyl cyclase activity, while Gq activates phospholipase $C \beta$, and G12/13 can activate small GTPase families [8]. The Gq family further can be divided into four members, such as Gq, G11, G14, and G15/16 [9, 10], and their respective $\alpha$ subunits [11]. Every protein in G protein signaling is subjected to regulation that may alter the expression, localization, or activity.

Chemokine and hormone receptors on lymphocytes have been shown to function as Gq protein-coupled GPCRs. These GqPCRs are regulated by different ligands in the immune system $[12,15]$. Abnormal regulation of these receptors leads to autoimmunity and a variety of autoimmune diseases induced by autoreactive lymphocytes. Furthermore, these abnormalities may lead to morbidity and mortality in individuals with autoimmune disorders [16-19]. Airway smooth muscle either contracts or relaxes to regulate airway patency and thus airflow. Different $\mathrm{G}$ proteins and their upstream receptors either promote or antagonize airway smooth muscle contraction. Therefore, he signaling proteins play important roles in asthma and other related morbidities [20]. GPCRs are also involved in cardiovascular functioning, such as contractility, and chronic processes, including hypertrophy, which contribute to the development of cardiovascular diseases, such as heart failure [21, 22].

As $G$ proteins are crucial in many cell processes and cell signaling, minor defects in $\mathrm{G}$ proteins can cause a disease. Approximately $25 \%$ of cancer types found in humans are due to mutations in the protein (Ras protein). This protein is known as the residue found in the GTP binding site that can retard the activity of GTPase enzyme. In abnormal conditions, once Ras is activated, it remains active for a long time and can constantly send signals for cell division [23].

Another type of mutation in the structure of G proteins that permanently change is the activity of $G_{\alpha}$ proteins (permanently active or inactive). Activating of mutation in those residues controls the GTPase activity and elevate the cAMP, causing undesirable proliferation of cells. Approximately $40 \%$ of pituitary tumors include this type of mutation. Inactive mutation is found in a gene, which transduces the $\alpha$ subunit and causes the night blindness, because this $\alpha$ unit is involved in visual signaling [24]. If there is a variation found in a gene that encodes $\beta$ subunit of $\mathrm{G}$ proteins, it can cause hypertension, obesity, and atherosclerosis [25].

The bacteria responsible for cholera and whooping cough targets specific $\mathrm{G}$ proteins by excreting some toxins and impede the normal signaling pathway. The cholera toxin is a heterodimeric protein found in the intestine of infected person. The $\beta$ subunit is present on the surface of intestinal epithelial cells and provide a pathway for the entrance of $\alpha$ subunit into the cell, where it is divided into two pieces, such as $\alpha 1$ and $\alpha 2$ subunit. The $\alpha 1$ subunit attaches with ARF6 (ADP-ribosylation factor) and converts into active form. This activation catalyzes the conversion of ADP-ribose from $\mathrm{NAD}^{+}$to arginine residue. The ADP-ribosylation is involved in the blockage of GTPase activity. Consequently, continuous activation of adenyl cyclase occurs, which increases the amount of cAMP and triggers the activation of PKA. Exchange of ions occurs in the cell, due to which, massive loss of water causes osmotic imbalance and severe dehydration. In the absence of rehydration therapy, such condition can be fatal [26, 27].

The toxin of whooping cough bacteria catalyzes the ADP-ribosylation and blocks the GDP-GTP exchange. This bacterium causes the infection of respiratory tract and destroys the epithelial cells. Cilia of epithelial cells is used in the removal of mucus, but after the destruction of these cells, rapid coughing occurs to get rid of mucus. However, the complete mechanism is not yet clear [28, 29].

As discussed above, activation/inhibition of GPCRs and heterotrimeric $\mathrm{G}$ proteins play a crucial role in the pathogenesis of various diseases. Inhibition of GPCR signaling by small inhibitors is a novel way to treat various pathological conditions. In fact, GPCRs have extremely high impact on drug discovery and approximately $30 \%$ of current drug targets are GPCRs [30-40]. Multiple different GPCRs are involved in various pathologies, such as cancer and pain; therefore, novel therapeutic strategies are there to focus on the pan-inhibition of GPCR signaling by small molecules in such pathologies [32]. Small molecules interacting with $G \beta \gamma$ subunits [33] or heterotrimeric $G$ protein signaling $[34,35]$ have shown particularly good anti-tumor and pain relief activities in animal models and could be used as an effective therapeutic option in future for cancer and pain. In heart patients, many current drug therapies target GPCRs to prevent hypertrophic signaling and improve clinical outcomes [36]. The small drugs compounds include $\beta$-adrenergic receptor blockers and angiotensin II receptor blockers [37]. Recently, it has been demonstrated that some GPCR ligands have a dual capacity to block hypertrophic signaling pathways and promote cardiac contractility or survival [38-40], a property that could improve overall cardiac function relative to conventional GPCR blockers.

\section{Conclusions}

$\mathrm{G}$ proteins and GPCRs play a crucial role in cell signaling, which can recognize the chemical and extracellular signals. GPCRs have a unique structure of seven-transmembrane receptors. Many types of GPCRs are found in human genome, and a slight change in the signaling of $\mathrm{G}$ proteins (mutation) can cause various diseases in a human body. Due to their central role in many human pathologies, GPCRs are the treatment target for several human diseases. A clear understanding of GPCR-mediated 
signaling in a disease state would be of help in designing therapeutic options (such as small signaling blockers). Therefore, there is a need to explore in detail the role of GPCRs signaling in human health and diseases.

\section{Acknowledgements}

The author would like to thank Dr. Muhammad Ali for his help in English language editing and proof-reading the manuscript.

\section{The author declares no conflict of interest.}

\section{References}

1. Latek D, Modzelewska A, Trzaskowski B, et al. (2012): G protein-coupled receptors--recent advances. Acta Biochim Pol 59: 515-529.

2. Suwa M, Sugihara M, Ono Y (2011): Functional and Structural Overview of G-Protein-Coupled Receptors Comprehensively Obtained from Genome Sequences. Pharmaceuticals 4: 652-664.

3. Baldwin JM (1994): Structure and function of receptors coupled to G proteins. Curr Opin Cell Biol 6: 180-190.

4. Tuteja N, Sopory SK (2008): Plant signaling in stress: G-protein coupled receptors, heterotrimeric G-proteins and signal coupling via phospholipases. Plant Signal Behav 3: 79-86.

5. Lefkowitz RJ, Shenoy SK (2005): Transduction of receptor signals by beta-arrestins. Science 308: 512-517.

6. Hubbard KB, Hepler JR (2006): Cell signalling diversity of the Gq $\alpha$ family of heterotrimeric $\mathrm{G}$ proteins. Cellular Signalling 18: 135-150.

7. Wettschureck N, Moers A, Offermanns S (2004): Mouse models to study G-protein-mediated signaling. Pharmacol Ther 101: 75-89.

8. Neves SR, Ram PT, Iyengar R (2002): G protein pathways. Science 296: 1636-1639.

9. Strathmann M, Simon MI (1990): G protein diversity: a distinct class of alpha subunits is present in vertebrates and invertebrates. Proc Natl Acad Sci USA 87: 9113-9117.

10. Wilkie TM, Scherle PA, Strathmann MP, et al. (1991): Characterization of G-protein alpha subunits in the Gq class: expression in murine tissues and in stromal and hematopoietic cell lines. Proc Natl Acad Sci USA 88: 10049-10053.

11. Mizuno N, Itoh H (2009): Functions and regulatory mechanisms of Gq-signaling pathways. Neurosignals 17: 42-54.

12. Misra RS, Shi G, Moreno-Garcia ME, et al. (2010): Gaq-containing $\mathrm{G}$ proteins regulate $\mathrm{B}$ cell selection and survival and are required to prevent B cell-dependent autoimmunity. J Exp Med 207: 1775-1789.

13. Svensson L, Stanley P, Willenbrock F, Hogg N (2012): The Galphaq/11 proteins contribute to T lymphocyte migration by promoting turnover of integrin LFA-1 through recycling. PLoS One 7: e38517.

14. Wang D, Zhang Y, He Y, et al. (2014): The deficiency of Gaq leads to enhanced T-cell survival. Immunol Cell Biol 92: 781-790.

15. Wang Y, Li Y, Shi G (2013): The regulating function of heterotrimeric $\mathrm{G}$ proteins in the immune system. Arch Immunol Ther Exp (Warsz) 61: 309-319.
16. Antonelli A, Ferrari SM, Giuggioli D, et al. (2014): Chemokine (C-X-C motif) ligand (CXCL) 10 in autoimmune diseases. Autoimmun Rev 13: 272-280.

17. Carvalho C, Calvisi SL, Leal B, et al. (2014): CCR5-Delta32: implications in SLE development. Int J Immunogenet 41: 236-241.

18. Choi JY, Ho JH, Pasoto SG, et al. (2015): Circulating follicular helper-like T cells in systemic lupus erythematosus: association with disease activity. Arthritis Rheumatol 67: 988-999.

19. Li Y, Wang Y, He Y, et al. (2013): Gaq gene promoter polymorphisms and rheumatoid arthritis in the Han Chinese population are not associated. Genet Mol Res 12: 1841-1848.

20. Penn RB, Benovic JL (2008): Regulation of Heterotrimeric G Protein Signaling in Airway Smooth Muscle. Proc Am Thorac Soc 5: 47-57.

21. Penela P, Murga C, Ribas C, et al. (2006): Mechanisms of regulation of $\mathrm{G}$ protein-coupled receptor kinases (GRKs) and cardiovascular disease. Cardiovasc Res 69: 46-56.

22. Tilley DG, Rockman HA (2006): Role of beta-adrenergic receptor signaling and desensitization in heart failure: new concepts and prospects for treatment. Expert Rev Cardiovasc Ther 4: 417-432.

23. Simanshu DK, Nissley DV, McCormick F (2017): RAS Proteins and Their Regulators in Human Disease. Cell 170: 17-33.

24. Lania AG, Mantovani G, Spada A (2006): Mechanisms of disease: Mutations of G proteins and G-protein-coupled receptors in endocrine diseases. Nat Clin Pract Endocrinol Metab 2: 681-693.

25. Thompson MD, Hendy GN, Percy ME, et al. (2014): G protein-coupled receptor mutations and human genetic disease. Methods Mol Biol 1175: 153-187.

26. Mangmool S, Kurose H (2011): Gi/o Protein-Dependent and -Independent Actions of Pertussis Toxin (PTX). Toxins (Basel) 3: 884-899.

27. Melien O, Sandnes D, Johansen EJ, Christoffersen T (2000): Effects of pertussis toxin on extracellular signal-regulated kinase activation in hepatocytes by hormones and receptor-independent agents: evidence suggesting a stimulatory role of G(i) proteins at a level distal to receptor coupling. J Cell Physiol 184: 27-36.

28. Nelson DL, Cox MM (2010): Lehninger Principles of Biochemistry, $6^{\text {th }}$ ed. W.H. Freeman, New York, USA.

29. Ghosh E, Kumari P, Jaiman D, Shukla AK (2015): Methodological advances: the unsung heroes of the GPCR structural revolution. Nature 16: 69-81.

30. Salon JA, Lodowski DT, Palczewski K (2011): The significance of $\mathrm{G}$ protein-coupled receptor crystallography for drug discovery. Pharmacol Rev 63: 901-937.

31. Overington JP, Al-Lazikani B, Hopkins AL (2006): How many drug targets are there? Nat Rev Drug Discov 5: 993-996.

32. Ayoub MA, Damian M, Gespach C, et al. (2009): Inhibition of Heterotrimeric G Protein Signaling by a Small Molecule Acting on Ga Subunit. J Biol Chem 284: 29136-29145.

33. Bonacci TM, Mathews JL, Yuan C, et al. (2006): Differential targeting of Gbetagamma-subunit signaling with small molecules. Science 312: 443-446.

34. Prévost GP, Lonchampt MO, Holbeck S, et al. (2006): Anticancer activity of BIM-46174, a new inhibitor of the heterotrimeric Galpha/Gbetagamma protein complex. Cancer Res 66: 9227-9234.

35. Favre-Guilmard C, Zeroual-Hider H, Soulard C, et al. (2008): The novel inhibitor of the heterotrimeric G-protein complex, 
BIM-46187, elicits anti-hyperalgesic properties and synergizes with morphine. Eur J Pharmacol 594: 70-76.

36. Tilley DG (2011): G Protein-Dependent and G Protein-Independent Signaling Pathways and Their Impact on Cardiac Function. Circ Res 109: 217-230.

37. Ma TK, Kam KK, Yan BP, Lam YY (2010): Renin-angiotensin-aldosterone system blockade for cardiovascular diseases: current status. Br J Pharmacol 160: 1273-1292.

38. Kim IM, Tilley DG, Chen J, et al. (2008): Beta-blockers alprenolol and carvedilol stimulate betaarrestin- mediated EGFR transactivation. Proc Natl Acad Sci U S A 105: 1455514560.

39. Tilley DG, Nguyen AD, Rockman HA (2010): Troglitazone stimulates betaarrestin- dependent cardiomyocyte contractility via the angiotensin II type $1 \mathrm{~A}$ receptor. Biochem Biophys Res Commun 396: 921-926.

40. Violin JD, DeWire SM, Yamashita D, et al. (2010): Selectively engaging $\beta$-arrestins at the angiotensin II type 1 receptor reduces blood pressure and increases cardiac performance. J Pharmacol Exp Ther 335: 572-579. 